\title{
The Nature of Low Temperature Carburized Layer
}

\section{Fazel Baniasadi ${ }^{1}$, Saeed Sovizi ${ }^{2}$, Peter Todoroff ${ }^{1}$, Poopak Amini ${ }^{2}$, Sirous Asgari $^{2 *}$}

${ }^{\mathbf{1}}$ Department of Materials Science and Engineering, Virginia Polytechnic Institute and State University, Blacksburg, USA.

${ }^{2}$ Department of Materials Science and Engineering, Sharif University of Technology, Tehran, Iran, P.O. Box 11365-9466.

*Corresponding Author: Professor, Department of Materials Science and Engineering, Sharif University of Technology, Tehran, Iran, PO Box 11365-9466.

\begin{abstract}
Carburizing of stainless steels at low temperatures (below $500^{\circ} \mathrm{C}$ ) develops a high content carbon layer, known for its high hardness. X-ray Diffraction investigation indicates that carburization treatment does not impact the structure of substrate; however, introduced carbon causes expansion in the carburized layer through the increase in d-spacing. Characterization of carbon concentration and hardness profiles indicate that carbon content gradually decreases while moving further into the substrate; and the origin of the increased hardness of the expanded layer arises from the super-saturated carbon content, following the solid solution strengthening theory. An area that is not well understood is in regard to the carburized layer's relation to the substrate and the significance in their differences. Using two grades of stainless steel, AISI 316L and PH 17-4, it was observed that the carburized layer is not a separate layer, but a higher carbon content version of the substrate.
\end{abstract}

Key Words: Low Temperature Carburizing, XRD, Optical Microscopy, Carburized Layer. 


\section{1- Introduction}

Stainless steels (SSs) are used significantly in chemical, nuclear, and petrochemical industries and many heavy duty applications like in hydraulic actuators due to their high corrosion resistance [1-5]. These alloys are also used as biomaterials due to the wide variance in mechanical and electrochemical properties [2]. However, low hardness and low wear resistance reduces their feasibility for specific applications. One of the methods for increasing hardness and wear resistance of the material's surface is through carburization. Carburization is the process of introducing carbon atoms into a material's surface through diffusion by subjecting the material to a high carbon environment at elevated temperatures, which increases their surface hardness [6-9]. However, the creation of carbides from substitution atoms, such as free chromium, dilutes the matrix from chromium and prevents the formation of a protective passivation layer of $\mathrm{Cr}_{2} \mathrm{O}_{3}$. It is well known that the passivation layer provides SSs well known corrosion resistance [1].

Another method for increasing hardness is quenching, however, this is not feasible for these alloys due to their high Nickel content which acts as an austenite stabilizer and prevents martensite formation $[3,10]$.

In recent years, studies have been conducted to investigate increasing the hardness and wear resistance without any loss of corrosion resistance [2]. Initial findings have shown that thermochemical treatment at low temperatures (below $500^{\circ} \mathrm{C}$ ) increases hardness without a decrease in corrosion resistance [6, 11-15]. Under these conditions, interstitial atoms such as carbon and nitrogen are highly mobile and easily diffuse. However, the energy required for the mobility of substitution atoms, such as chromium, is insufficient; resulting in kinetically constrained or immobile atoms. Due to these conditions, fewer carbide or nitride precipitates are formed in comparison to the carbide formed at higher temperatures [16-22] and the 
content of the diffused interstitial atoms in the surface is much higher than the equilibrium state [23]. Through the introduction of these interstitial atoms in the surface, the affinity of lattice expansion is suppressed by the constant volume of substrate results in the formation of high compressive stresses, which consequentially cause an increase in fatigue resistance [24]. Many researchers have considered the carburized layer as a separate phase, often termed as the "S phase" on austenitic SSs and the "M phase" on martensitic SSs $[6,12,18,25]$. In this study, the validity of this claim was investigated. Two types of SSs PH 17-4 as a martensitic SS and AISI 316L as an austenitic SS, were selected for low temperature gas carburization. The relationship between the carburized layer and the associated substrate was investigated with preliminary investigation of structure and microstructure.

\section{2- Experimental Procedure}

Chemical composition of AISI 316L and PH17-4 SSs are given in Table 1 and 2. The steel samples underwent low temperature gas carburization using a variation of a common gas media ( $38 \mathrm{vol} \% \mathrm{CO}, 2 \mathrm{vol} \% \mathrm{CO}_{2}$ and $60 \mathrm{vol} \% \mathrm{H}_{2}$ ) at $450^{\circ} \mathrm{C}$ for 18 hours[26]. Separate samples of each material were annealed at the same temperature and carburizing duration to compare with carburized samples. Finally, all of the samples were cooled to room temperature in the furnace.

Table.1: Chemical composition of AISI 316L SS.

\begin{tabular}{|c|c|c|c|c|c|c|c|c|c|c|}
\hline Element & $\mathrm{C}$ & $\mathrm{Mn}$ & $\mathrm{P}$ & $\mathrm{S}$ & $\mathrm{Si}$ & $\mathrm{Cr}$ & $\mathrm{Ni}$ & $\mathrm{Mo}$ & $\mathrm{N}$ & $\mathrm{Fe}$ \\
\hline $\begin{array}{c}\text { Weight } \\
\text { Percent }\end{array}$ & 0.018 & 1.45 & 0.031 & 0.026 & 0.72 & 16.84 & 10.19 & 2.1 & 0.086 & Balance \\
\hline
\end{tabular}


Table 2: Chemical composition of PH 17-4 SS.

\begin{tabular}{|c|c|c|c|c|c|c|c|c|c|c|c|c|c|}
\hline Element & $\mathrm{C}$ & $\mathrm{Mn}$ & $\mathrm{P}$ & $\mathrm{S}$ & $\mathrm{Si}$ & $\mathrm{Cr}$ & $\mathrm{Ni}$ & $\mathrm{Cu}$ & $\mathrm{Ta}$ & $\mathrm{S}$ & $\mathrm{N}$ & $\mathrm{O}$ & $\mathrm{Fe}$ \\
\hline $\begin{array}{l}\text { Weight } \\
\text { Percent }\end{array}$ & 0.07 & 0.93 & 0.05 & 0.03 & 0.83 & 17 & 4.53 & 3.81 & 0.3 & 0.001 & 0.001 & 0.002 & Balance \\
\hline
\end{tabular}

After their duration in the furnace, XRD was performed with the EQuinox 1111 using a $\mathrm{CuK} \alpha$ tube on the carburized and annealed samples. The specimens were mounted in a molding polymer and then cleaned. The specimens were cleaned with $\mathrm{SiC} 3000$ grit sandpaper, then polished using a suspension solution of $50 \mathrm{~nm}$ alumina particles, and were then finally etched with a Kalling etchant (10 $\mathrm{gr} \mathrm{CuCl}_{2}$, $100 \mathrm{~mL} \mathrm{HCl}, 100 \mathrm{~mL}$ Methanol) for 40 seconds. Optical microscopy was then conducted to investigate the microstructure.

PHI 680 Scanning Auger Microprobe was used for Auger electron spectroscopy (AES) to calculate carbon concentration at different depths. Auger spectrum was taken first from the surface of the samples and then Argon sputtering was used at different depths (Fig. 4). Uncertainties in the reported experimental values were estimated by the method suggested by. Carbon concentration was measured until there was no significant change in the concentration of carbon for both samples, which was measured at a depth of $48 \mu \mathrm{m}$. AES tests were conducted ten times at each depth with the average calculated after the elimination of abnormal results. The hardness at each depth was calculated using a Nikon QM microhardness apparatus. At each instance, a $1 \mathrm{~N}$ force was applied for 15 seconds using a spherical indenter with an impression to ball diameter ratio (d/D) of 0.375 .

To investigate the coherency of the expanded layer, three point bending tests were performed on the carburized samples (Fig.1). Samples were subjected to 1-2\% plastic deformation as indicated by their dynamic stress-strain diagrams during the 
bending tests. The behavior of slip lines near the interfaces were investigated via optical microscopy using Nomarski contrast.

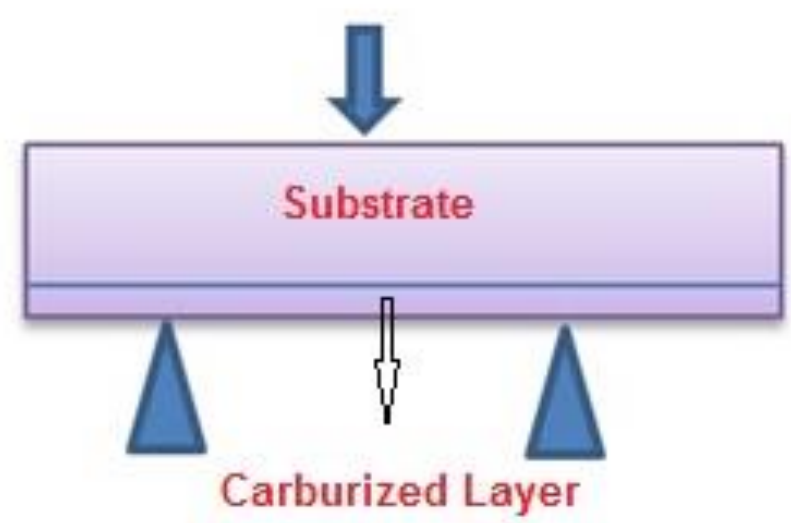

Fig.1: Schematic figure of three points bending test.

\section{3- Result and Discussion}

\section{3-1- XRD and AES Investigation}

Fig. 2 shows XRD results of carburized layers. Vertical red lines show the angles of diffraction planes in annealed samples.

Diffraction planes of the carburized layer of AISI 316L SS show an austenitic microstructure akin to the substrate with similar results for PH 17-4 SS. Diffracted angles of the carburized layers shift to lower angles in comparison to that of the annealed samples. This is due to the diffusion of carbon atoms into the interstitial sites, increasing the d-spacing in carburized layer. Peak width also increased for the carburized samples due to the Paraequilibrium carbon diffusion in the surface which causes distortion in crystal structure and residual compressive stress[26]. 

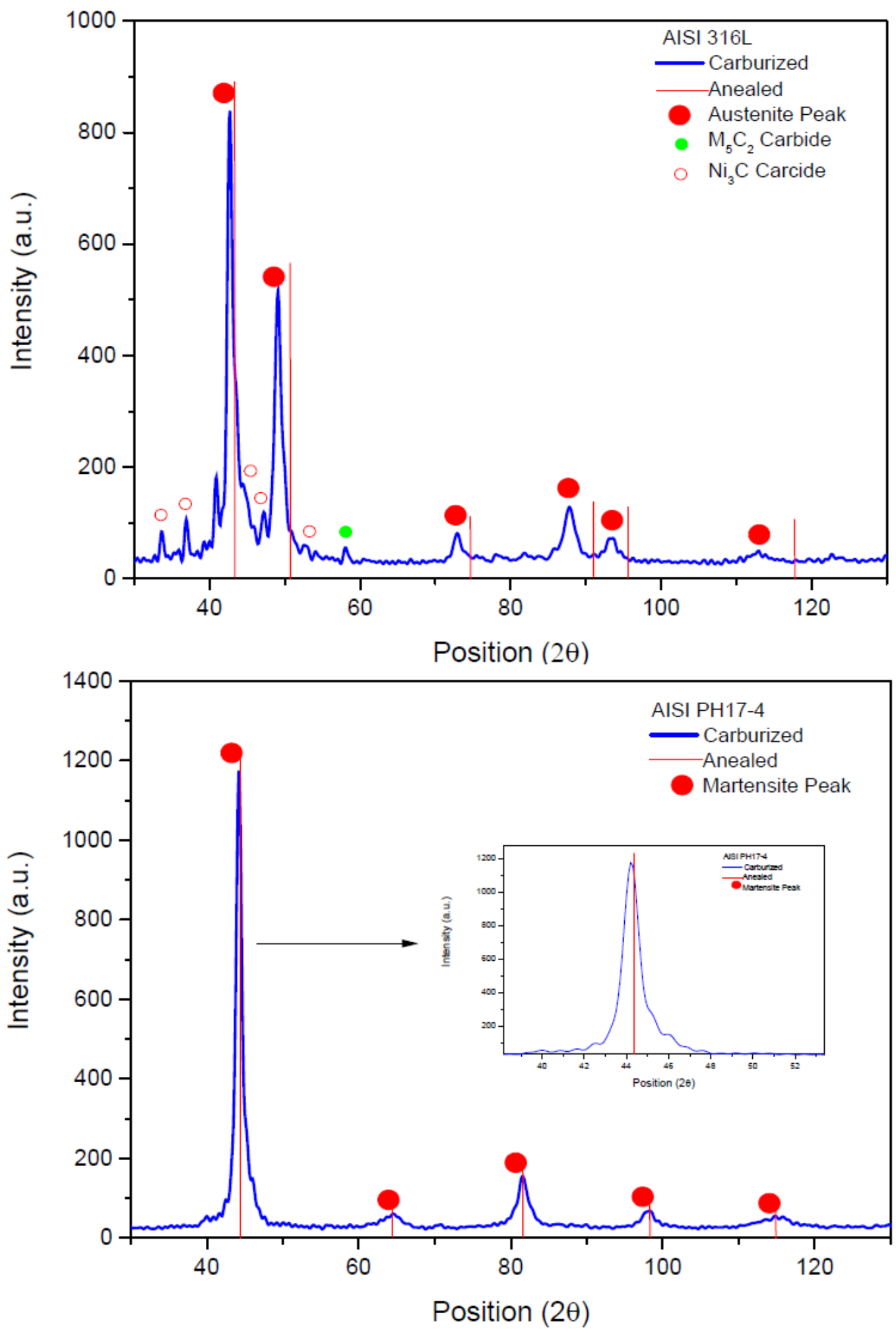

Fig.2: X-ray diffraction of low temperature carburized samples (black diagram), and identical diffracted planes of annealed sample (vertical red lines) a) 316L SS and b) PH 17-4 SS. 
Cross sectional images of carburized samples are shown in Fig.3. The featureless layer in these images is the carburized layer. For both SSs, there are no observable precipitates in the expanded layer, suggesting that the formed carbides in the process are negligible. The sample preparation processes of grinding, polishing, and etching revealed a large contrast in topography between the substrate and the carburized/extended layer. This suggests that the carburized layer is more corrosion resistant, and exhibits a higher hardness and wear resistance than the substrate.

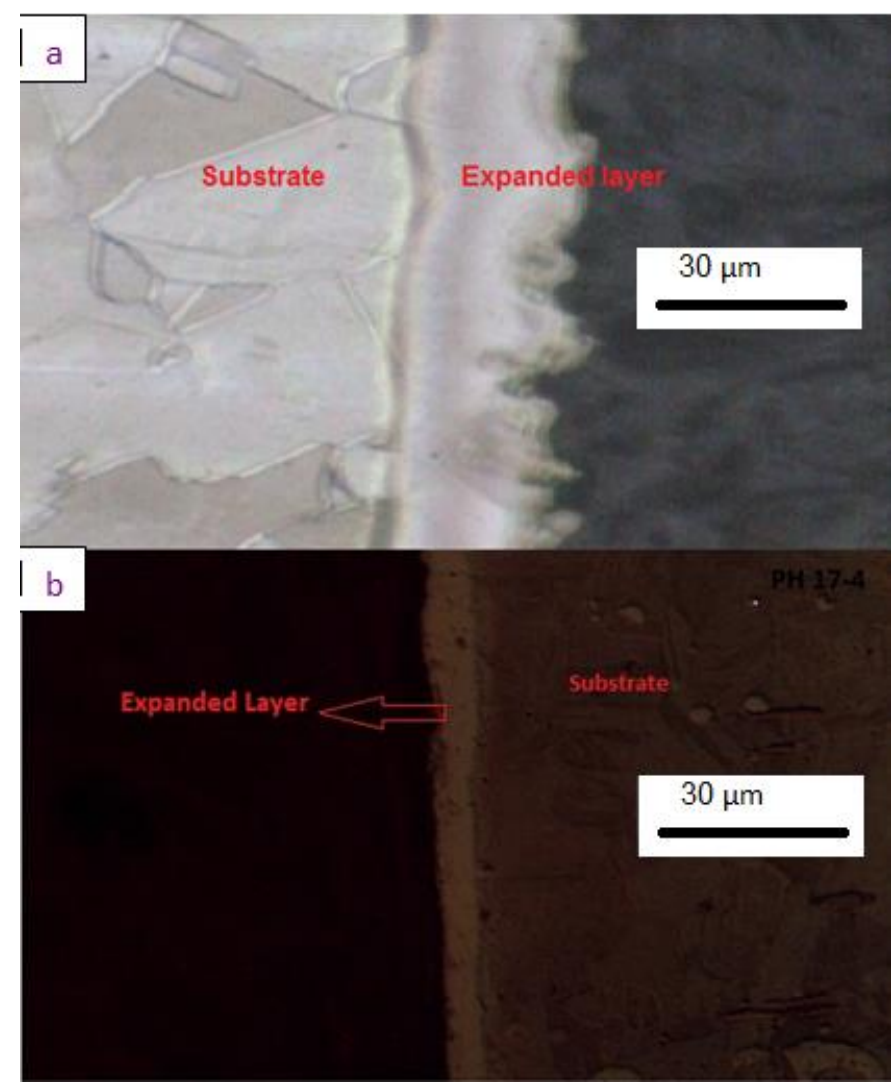

Fig.3: Cross sectional image of carburized samples a) 316L and b) PH 17-4 SSs.

Carbon concentration and hardness profiles are given in Fig.4. The carbon content adjacent to the surface for the carburized specimens reaches up to 13 at. \% for the 316L and 11at\% for PH 17-4, but carbon content in the matrices are nearly zero, indicating the carburization did not affect the substrate. As shown in Table 1 and 2, 
the carbon concentration at the equilibrium condition is less than 0.015 at. $\%$ for both SSs Low temperature gas carburization increased the content of diffused carbon to nearly 860 times more than the equilibrium condition. Optical microscopy investigation supports this claim with no visible precipitate development at the given concentration of carbon.

These diagrams also show that the carbon concentration drops significantly, approaching zero at probed depths of $31 \mu \mathrm{m}$ for $316 \mathrm{~L}$ and $13 \mu \mathrm{m}$ for PH 17-4. This indicates that the depths of expanded layers are about $31 \mu \mathrm{m}$ and $13 \mu \mathrm{m}$, respectively. Carbon content is constant for the first $4 \mu \mathrm{m}$ of austenitic carburized layer, and $3 \mu \mathrm{m}$ for the martensitic carburized layers. These constant concentrations support the Trapping/De-trapping model [11, 27, 28]. Within the constant carbon content regions, all interstitial sites have been filled with carbon atoms, showing that extra carbon atoms have diffused into the sample [6]. 

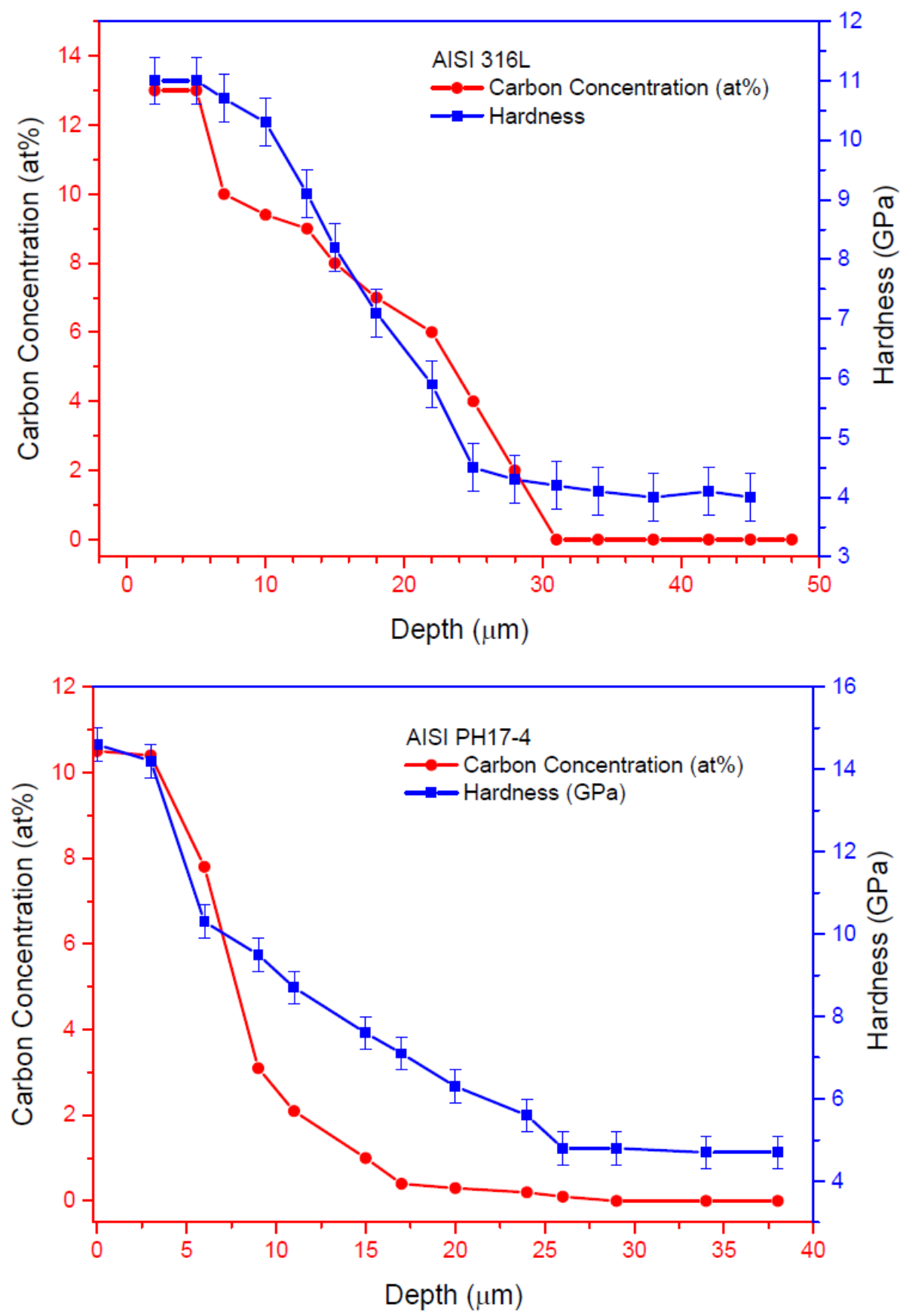

Fig.4: In-Depth carbon concentration and hardness of carburized a) 316L and b) PH 17-4 SSs. Note: error bars are not included for "Carbon Concentration (at\%)" because due to their size of $0.01 \%$.

As it can be seen in Fig. 4, hardness in the surface reaches $11 \mathrm{GPa}$ for 316L and $15 \mathrm{GPa}$ for $\mathrm{PH} 17-4$; however, hardness in the matrix is about 4 and $5 \mathrm{GPa}$, respectively. The high content of diffused carbon in the interstitial sites increases 
hardness according to solid solution strengthening theory [29]. For both steels, the hardness is constant in the substrate below the expanded layer as supported by the similar concentration-depth and cross sectional metallographic images. This supports the claim that the carburized layer thicknesses are $31 \mu \mathrm{m}$ and $13 \mu \mathrm{m}$ for 316L and PH 17-4, respectively. Carbon concentration and hardness profiles are similar, so it can be concluded that hardness is proportional to interstitial carbon content in the layer.

\section{3-2- Coherency of Expanded Layers}

Investigation on the crystallographic relationship between the expanded layers and their substrates was performed via optical microscopy with grain structure and dislocation behavior analysis at interface grains. Complications in optical microscopy analysis existed due to the high corrosion resistance of the expanded layers during the process of etching. Further attempts at etching would have consequentially compromised the substrates. It was observed that very few grains were visible in the extended layer. However, of the grains observed, they continued across the interfacial boundary from the substrate into the extended layer without any deviation in microstructure (Fig. 5a). The absence of grain boundary deviation across this interfacial boundary indicates that the carburized layer is coherent and part of the substrate; it is not a separate layer. Fig.5a shows a twin which is marked with a red arrow; this twin extends from the austenitic matrix into the carburized layer. Fig.5b also shows boundaries (marked with black arrows) which continue to the middle of carburized layer without any change in direction. This further suggests no alteration in the microstructure as the substrate transitions into the carburized region and indicates that no processes of nucleation and growth have occurred. The micrographs appear to indicate a definitive difference between the substrate and the carburized region, however, this perceived boundary from 
Nomarski contrast is due to differences in topography that can be attributed to variations in the corrosion and wear resistance of the material.
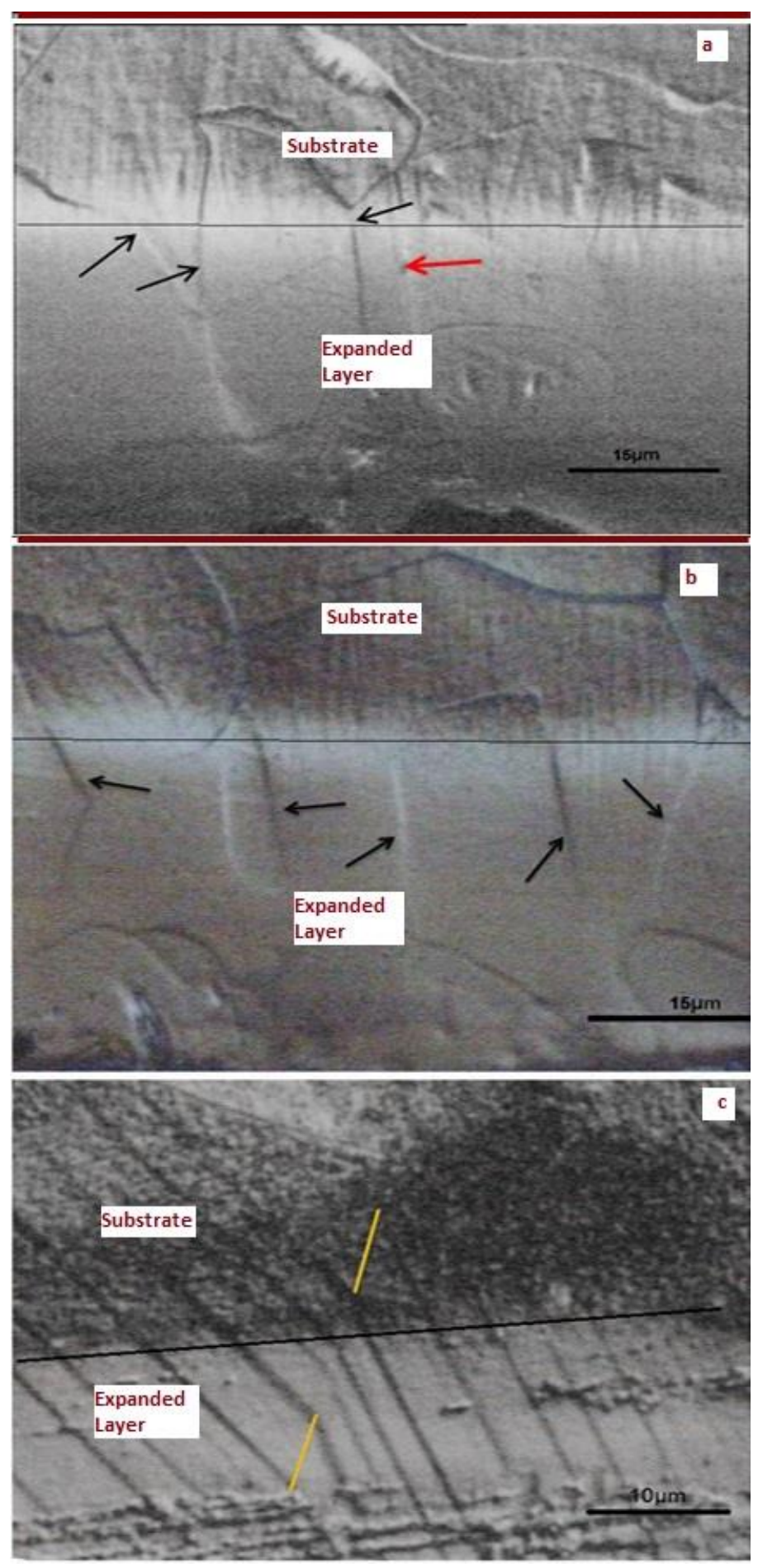

Fig.5: cross sectional images of carburized 316L sample with Nomarski contrast of a) grains and twins b) just grains c) deformed sample. 
Further support of this claim can be proven by analysis of slip lines as shown in Fig.5c. Slip lines are well understood to change their direction at grain boundaries due to the mis-match of slip plane orientations. It is mostly seen that these slip lines do not exhibit any change in direction while crossing into the carburized region. This proves identical structure between the substrate and the carburized region. A grain boundary extending across the substrate - carburized region interface is observed via the slip line behavior (marked in yellow lines). This grain boundary is observed due to the slip lines changing their direction. This further agrees with the assertion that there is no structural difference.

For PH 17-4 SS in Fig 6a, after the three-point bending test was conducted, it was observed that slip lines continue from the carburized layer to the substrate without any change in direction. Similar to the $316 \mathrm{~L}$ specimen, there were some martensitic formations that passed from the carburized layer into the substrate. This means that each of these shared martensitic formations is a phase with different amount of carbon in adjacent layers (Fig.6b). Hence, it can be concluded that there would be no nucleation and growth for the expanded layer, and also this is not a separate layer, but this is the substrate just with different amount of carbon. 


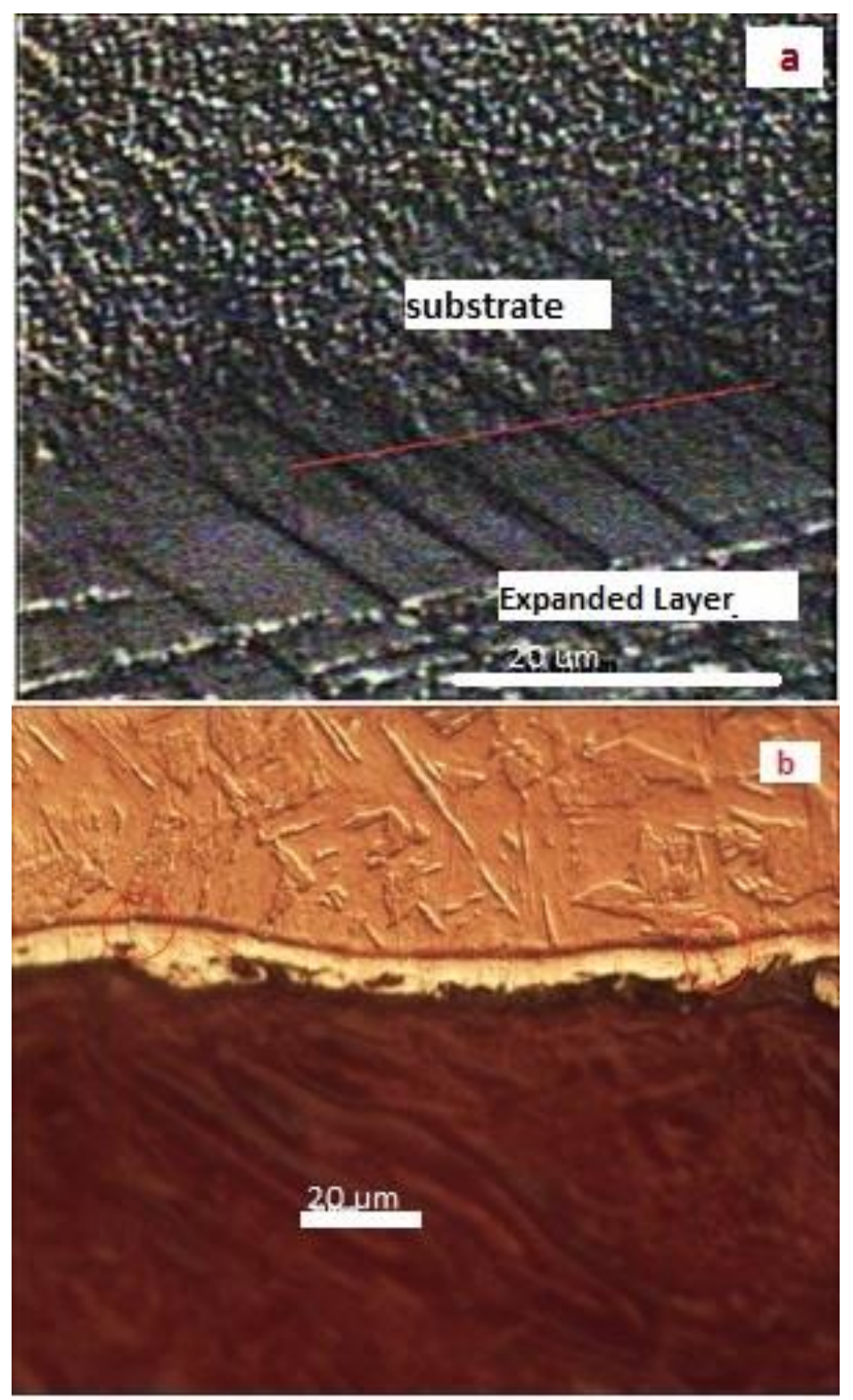

Fig.6: cross sectional images of PH 17-4 carburized sample with nomarski contrast of a) deformed sample and b) Martensites.

\section{Conclusion}

The carburization of 316L SS and for PH 17-4 SS at a low temperature of 500 Centigrade produced a carburized layer thicknesses of $31 \mu \mathrm{m}$ and $13 \mu \mathrm{m}$, respectively. These carburized layers has the following characteristics: 
Structures of the carburized layers were the same as both the substrates in the austenitic SS and martensitic SS, respectively. Also, low amounts of carbides were found in 316L SS that could not be verified through optical microscopy. Excessive hardness of these layers is due to the presence of supersaturated carbon content in the surface, which can be justified according to solid solution strengthening theory. Crystallographic directions, grains, or martensitic formation of carburized layers are as of their matrixes. Through static observation of the interface between substrate and the carburized layer, it was determined that no nucleation and growth occurred. In support of the solid solution strengthening theory, It was concluded that that introduction of carbon into the surface did not cause a change in the crystallographic structure.

\section{Acknowledgment}

The authors of this paper would like to acknowledge the support of Professor Seyyed Masoud Seyyed Ahmadian who provided generous access to the use of his laboratory and equipment.

\section{References}

1. Sedriks, A.J., Corrosion of stainless steel, 2. 1996.

2. Dong, H., S-phase surface engineering of $\mathrm{Fe}-\mathrm{Cr}$, Co-Cr and Ni-Cr alloys. International Materials Reviews, 2010. 55(2): p. 65-98.

3. Lo, K.H., C.H. Shek, and J. Lai, Recent developments in stainless steels. Materials Science and Engineering: R: Reports, 2009. 65(4): p. 39-104.

4. Sharifi, S., et al., Leakage fault detection in Electro-Hydraulic Servo Systems using a nonlinear representation learning approach. ISA Transactions, 2018. 73: p. 154-164.

5. Sharifi, S., et al. Multi-class fault detection in electro-hydraulic servo systems using support vector machines. in Robotics and Mechatronics (ICROM), 2016 4th International Conference on. 2016. IEEE.

6. Leyland, A., et al., Low temperature plasma diffusion treatment of stainless steels for improved wear resistance. Surface and Coatings Technology, 1993. 62(1): p. 608-617.

7. Suh, B.-S. and W.-J. Lee, Surface hardening of AISI 316L stainless steel using plasma carburizing. Thin Solid Films, 1997. 295(1): p. 185-192.

8. Parrish, G., Carburizing: microstructures and properties. 1999: Asm International.

9. Nazari, A. and S. Farhad, Heat generation in lithium-ion batteries with different nominal capacities and chemistries. Applied Thermal Engineering, 2017. 125: p. 1501-1517. 
10. Vitek, J., A. Dasgupta, and S. David, Microstructural modification of austenitic stainless steels by rapid solidification. Metallurgical Transactions A, 1983. 14(9): p. 1833-1841.

11. Tsujikawa, M., et al., Surface material design of 316 stainless steel by combination of low temperature carburizing and nitriding. Surface and Coatings Technology, 2005. 200(1): p. 507511.

12. Souza, R.M.d., et al., Structure and properties of low temperature plasma carburized austenitic stainless steels. Surface and Coatings Technology, 2009. 204(6): p. 1102-1105.

13. Williams, P.C. and S.V. Marx, Low temperature case hardening processes. 2000, Google Patents.

14. Hwang, K.-S., L.-H. Cheng, and Y.-C. Lu, Low-temperature stainless steel carburization method. 2013, Google Patents.

15. A.E. Pirbazari, P.M., B.F. Kisomi, $\mathrm{Co} / \mathrm{TiO}_{2}$ nanoparticles: preparation, characterization and its application for photocatalytic degradation of methylene blue. Desalin, Water Treat 2017. 63: p. 283-292.

16. Ernst, F., Y. Cao, and G. Michal, Carbides in low-temperature-carburized stainless steels. Acta Materialia, 2004. 52(6): p. 1469-1477.

17. Ernst, F., et al., Carbide precipitation in austenitic stainless steel carburized at low temperature. Acta Materialia, 2007. 55(6): p. 1895-1906.

18. Sun, Y., Kinetics of low temperature plasma carburizing of austenitic stainless steels. Journal of Materials Processing Technology, 2005. 168(2): p. 189-194.

19. Adachi, S. and N. Ueda, Combined plasma carburizing and nitriding of sprayed AISI 316L steel coating for improved wear resistance. Surface and Coatings Technology, 2014. 259: p. 44-49.

20. Najdahmadi, A., A. Zarei-Hanzaki, and E. Farghadani, Mechanical properties enhancement in Ti29Nb-13Ta-4.6 Zr alloy via heat treatment with no detrimental effect on its biocompatibility. Materials \& Design (1980-2015), 2014. 54: p. 786-791.

21. Yarahmadi, M., H.M. Goudarzi, and M. Shafii, Experimental investigation into laminar forced convective heat transfer of ferrofluids under constant and oscillating magnetic field with different magnetic field arrangements and oscillation modes. Experimental Thermal and Fluid Science, 2015. 68: p. 601-611.

22. Goudarzi, H.M., M. Yarahmadi, and M.B. Shafii, Design and construction of a two-phase fluid piston engine based on the structure of fluidyne. Energy, 2017. 127: p. 660-670.

23. Cao, Y., F. Ernst, and G. Michal, Colossal carbon supersaturation in austenitic stainless steels carburized at low temperature. Acta Materialia, 2003. 51(14): p. 4171-4181.

24. Agarwal, N., et al., Enhanced fatigue resistance in $316 \mathrm{~L}$ austenitic stainless steel due to lowtemperature paraequilibrium carburization. Acta Materialia, 2007. 55(16): p. 5572-5580.

25. Christiansen, T. and M.A. Somers, Low temperature gaseous nitriding and carburising of stainless steel. Surface Engineering, 2005. 21(5-6): p. 445-455.

26. Baniasadi, F., et al., Thermal stability investigation of expanded martensite. Surface and Coatings Technology, 2016. 300: p. 87-94.

27. Williamson, D., et al. Stainless Steel 2000. in Proceedings of an International Current Status Seminar on Thermochemical Surface Engineering of Stainless Steels, The Institute of Materials, London. 2001.

28. Tsujikawa, M., et al., Behavior of carbon in low temperature plasma nitriding layer of austenitic stainless steel. Surface and Coatings Technology, 2005. 193(1): p. 309-313.

29. Neuhäuser, H. and C. Schwink, Solid solution strengthening. Materials science and technology, 1993. 